\title{
Pulsed Energy Systems for Generating Plasmas
}

\author{
M. Franklin Rose ${ }^{*}$ and Z. Shotts ${ }^{\dagger}$ \\ Radiance Technologies, Inc. Huntsville, AL 35805
}

This paper will describe the techniques needed to electrically generate highly ionized dense plasmas for a variety of applications. The components needed in pulsed circuits are described in terms of general performance parameters currently available from commercial vendors. Examples of pulsed systems using these components are described and technical data from laboratory experiments presented. Experimental data are given for point designs, capable of multi-megawatt power levels.

\section{Nomenclature}

$\begin{array}{ll}\mathrm{E} & =\text { electric field } \\ \mathrm{K} & =\text { life in number of charge-discharge cycles } \\ \mathrm{DRPT} & =\text { double resonant pulse transformer } \\ \mathrm{L} & =\text { inductance } \\ \mathrm{C} & =\text { capacitance } \\ \mathrm{K} & =\text { coupling factor } \\ \mathrm{VIG} & =\text { vector inversion generator } \\ \beta & =\text { efficiency factor } \\ \mathrm{V} & =\text { voltage } \\ \mathrm{I} & =\text { current } \\ \mathrm{n} & =\text { number of turns } \\ \mathrm{R} & =\text { resistance } \\ \mathrm{D} & =\text { VIG diameter } \\ \tau & =\text { generator rise time } \\ \mathrm{l} & =\text { line length } \\ \varepsilon & =\text { dielectric constant } \\ \mathrm{c} & =\text { velocity of light } \\ \mathrm{MS} & =\text { switch }\end{array}$

\section{Introduction}

$\mathrm{T}$ The ability to generate highly ionized dense plasmas in the laboratory critically depend on the nature of the electrical energy source, the method of formatting the energy for optimal coupling to the plasma and the evolution of the electrical characteristics of the plasma. Plasmas in the laboratory begin as a highly resistive gas and rapidly evolve to a low resistance state as the gas is ionized and heated by fast injection of electrical energy. The evolution to the low impedance load places unique demands on the electrical system, sometimes necessitating two pulsed systems to effective couple energy into the plasma. In any case, the plasma is a variable impedance load and that makes it difficult to produce effective impedance matching between source and load. These plasma conditions are typical of those needed for pulsed plasma electric propulsion in space and in experimental devices such as the dense plasma focus. In general, fast rising high voltages and currents are needed. The systems to generate these conditions consist of an energy storage component, switches, pulse forming network if needed, and transmission lines to deliver the energy to the load. There are a wide range of components and techniques available. In this

\footnotetext{
*Vice President for Research, 350 Wynn Drive, Associate Fellow.

' Senior Systems Engineer, 350 Wynn Drive.
} 
paper, we are concerned with ultra-compact pulsed systems capable of long life. Further, these pulsed systems are as "simple as possible" with minimal numbers of components. We will describe some of the most promising techniques and provide illustrative examples from laboratory experiments aimed at such long-life applications as pulsed electric propulsion.

\section{Summary of Component Technologies}

Energy storage capacitors are essential for almost all of the schemes for producing pulsed plasmas. Many times, the application require the capacitors to store substantial quantities of energy, be subjected to voltage reversal, and utilized at a repetition rate that may require innovative thermal management techniques to eliminate thermally induced failures. For pulsed capacitive systems, the system mass is proportional to the specific energy of the storage media and the energy desired in any pulsed event. Table 1 illustrates the approximate state of the art in advanced capacitor technology relevant to pulsed plasma formation.

Table 1. Representative Relevant Capacitor Technologies

\begin{tabular}{|l|l|l|l|l|}
\hline Type & Voltage range & $\begin{array}{l}\text { Specific Energy } \\
\mathbf{J} / \mathbf{K g}\end{array}$ & $\begin{array}{l}\text { Life in number of } \\
\text { cycles }\end{array}$ & Comments \\
\hline $\begin{array}{l}\text { Polymer film } \\
\text { In oil bath or } \\
\text { metallized film }\end{array}$ & $>30 \mathrm{KV}$ & $>15$ & $>10^{10}$ & $\begin{array}{l}\text { Voltage reversal } \\
<20 \% \\
\text { Low ESR and ESL }\end{array}$ \\
\hline $\begin{array}{l}\text { Mica } \\
\text { Reconstituted film }^{2}\end{array}$ & $>10 \mathrm{KV}$ & $<10$ & $>10^{10}$ & $\begin{array}{l}\text { Low ESR and ESL } \\
\text { Life is specific } \\
\text { power limited }\end{array}$ \\
\hline Ceramic $^{2}$ & $>10 \mathrm{KV}$ & $<10$ & $<10^{6}$ & $\begin{array}{l}\text { Low ESR and ESL } \\
\text { Piezoelectric } \\
\text { Limited life }\end{array}$ \\
\hline
\end{tabular}

From the above table, it is obvious that the capacitor technologies most desirable for applications that require long life with minimal volume are the film type or those that are made up of reconstituted mica. The best data on cycle life in capacitors is that taken in a program to develop isotope separation techniques based on laser excitation ${ }^{1}$. For a given specific energy for a capacitor, there is also a specification of the amount of voltage reversal that the unit can take and still maintain high life in terms of numbers of charge-discharge cycles. Life in terms of numbers of charge discharge cycles is given approximately by:

$$
\mathrm{K}=\sim\left(\mathrm{E}_{\mathrm{I}} / \mathrm{E}_{\mathrm{m}}\right)^{8}
$$

Where $\mathrm{K}$ is the life in numbers of charge-discharge cycles, $E_{\mathrm{I}}$ is the intrinsic strength of the dielectric, and $E_{m}$ is the maximum working electric field. Reducing the working stress by a factor of two, results in an increase in life of $2^{8}$ while reducing the working stress will increase the size of the energy storage unit, it is a means of extending the life of a system almost indefinitely. Although there are new capacitor technologies emerging ${ }^{2}$ which would provide a higher specific energy, their life and loss mechanisms have not been explored sufficiently to allow general applicability in commercial markets. 


\section{Switch Technologies}

The switch technology for long life repetitive plasma generation is extremely demanding. To date, there is no reported switch in the literature capable of meeting all of the requisite parameters necessary for long life with continuous operation at high power levels and high $\mathrm{dV} / \mathrm{dt}$. If long life is not an issue, Spark gaps and pseudospark switches can meet all of the requisite parameters. Similarly, solid state switches while capable of life, have never been demonstrated under the stringent requirements that demand high $\mathrm{dV} / \mathrm{dt}$ and $\mathrm{I}$. In current embodiments the best solid state switches have hold off levels of approximately $5 \mathrm{kV}$ for an individual element and a dI/dt of less than 20 $\mathrm{kA} / \mathrm{us}$. The literature does contain examples of high di/dt but life under these conditions is unknown. Table 1 lists high power switch technologies that could be used in pulsed plasma generators. The references quoted are typical of the literature and not intended to be all inclusive. The proceedings of the IEEE International Pulsed Power Conferences and the International Modulator Symposia are rich sources of material for designing systems for plasma generation.

Table 2: Candidate Switch Technologies for Repetitive Pulsed Power Systems

\begin{tabular}{|l|l|l|l|l|l|}
\hline Switch & Voltage kV & $\begin{array}{l}\text { Maximum } \\
\text { Current kA }\end{array}$ & dI/dt kA/us & $\begin{array}{l}\text { Approximate } \\
\text { Life Hz }\end{array}$ & Comments \\
\hline Spark Gap & $>50$ & $>100$ & $>100$ & $<10^{6}$ & $\begin{array}{l}\text { Life limited by } \\
\text { electrode } \\
\text { erosion }\end{array}$ \\
\hline $\begin{array}{l}\text { Pseudo } \\
\text { Switch spark }\end{array}$ & 35 & $>20$ & $>20$ & $\begin{array}{l}\text { Life limited by } \\
\text { electrode } \\
\text { erosion }\end{array}$ \\
\hline Thyristor $^{5}$ & $\sim 5$ & 150 & $\sim 10^{9}$ & $\begin{array}{l}\text { Low voltage in } \\
\text { single unit }\end{array}$ \\
\hline IGBT & & 3.5 & 95 & $>10^{8}$ & $\begin{array}{l}\text { Low voltage in } \\
\text { single unit }\end{array}$ \\
\hline Magnetic $^{8,9}$ & $30-150$ & $>100$ & $>100$ & $\begin{array}{l}\text { Must be used } \\
\text { in pulsed } \\
\text { configuration }\end{array}$ \\
\hline
\end{tabular}

Solid state switches when operated within acceptable parameter ranges have essentially unlimited life. Similarly, magnetic switches based on saturation of magnetic materials within a core structure have been shown to be essentially limited to insulation failures in the feed circuits rather than in the intrinsic properties of the materials themselves 9 .

\section{Pulse Transformation Techniques}

\section{Dual Resonant High Voltage Pulse Transformer}

Since we are considering pulsed plasmas, some means of generating the necessary transient high voltages is necessary. The most common form of high voltage generator is the Marx generator ${ }^{3}$ that consists of capacitors, charged in parallel to low voltage by a suitable power supply and then discharged in series where the individual 
voltages add. This technique allows slow charging but can supply sub-microsecond rising pulses at voltages as high as megavolts with total energy delivered determined by the size of the individual capacitors. In most embodiments, the Marx circuit has one switch per stage which adds complexity and presents triggering difficulties. However, for electrical pulses which are a few microseconds in duration, dual resonant pulse transformers (DRPT) offer a more compact and reliable method of achieving high voltages than the more commonly used Marx generators and fast rising wave forms can be achieved by a "peaking switch" that transfers the energy to a load. Figure 1 shows a simple schematic of the key component of a pulsed electrical system capable of accepting low voltage input and delivering high voltage pulses to a load at high repetition rates. The DRPT and the wave forms in both the primary and secondary sides of the circuit are shown. Note the phase relationship and the fact that the energy stored in the primary circuit is resonantly transferred to the secondary, and as time progresses, back to the primary side of the DRPT. In a system, the energy stored in the secondary capacitor at high voltage would be diverted to a load at peak voltage. If the coupling factor for the DRPT is 0.6 , the energy transfer is in principle $100 \%$ but switch losses and stray inductance limit practical devices to $90-95 \%$.

This type of transformer has a low voltage capacitor, $C_{1}$, capable of storing all of the energy needed for a pulse, connected in series with an appropriate switch, $S_{1}$, and the primary of the DRPT with inductance $L_{1}$. The secondary side of the DRPT similarly has secondary inductance $L_{2}$ and a capacitor $C_{2}$. The condition for dual resonance is essentially that:

$$
\mathrm{L}_{1} \mathrm{C}_{1}=\mathrm{L}_{2} \mathrm{C}_{2}
$$

Making $L_{2}>L_{1}$ requires that $C_{2}<C_{1}$ if dual resonance is to be maintained. Neglecting losses, by conservation of energy, the voltage on $\mathrm{C}_{2}$ must increase if $\mathrm{L}_{2}$ is greater than $\mathrm{L}_{1}$. It is obvious that any voltage multiplication factor can be in principle achieved. It can be shown ${ }^{23}$ that for a coupling factor $\mathrm{K}$ of 0.6 , complete energy transfer from the primary side of the transformer to the secondary side occurs on the second cycle of oscillation in the secondary. The coupling factor of 0.6 allows for considerable spacing between the primary and secondary sides of the DRPT. Further, no magnetic core is necessary for tight coupling from primary to secondary and greatly reduces the weight of the system. It is possible to readily achieve efficiencies greater than $90 \%$ in a carefully designed system. This component allows a low voltage input to be converted to a high voltage at a rate determined by the design resonant frequency which is under the control of the experimenter. The literature is filled with examples of applications of this technique. ${ }^{24-27}$

\section{Vector Inversion Generators}

The Vector Inversion Generator ${ }^{10}$ (VIG) is a unique combination of capacitive energy storage and a voltage multiplier in one compact unit. It effectively eliminates the need for multiswitching technology and discrete capacitive storage elements in devices designed to produce high voltage, high power pulses. The distributed nature of the energy store allowed for flexible design and proved to be volumetric and mass efficient - greater than $10 \mathrm{MW} / \mathrm{kg}$ for individual pulses. The Vector Inversion Generator provides a precisely controllable method for producing high voltage high power pulse with a predetermined rise time in a single dynamic step, requiring only one active component.

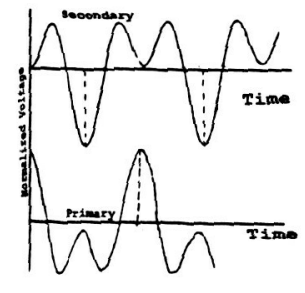

Figure 1. Double resonant pulse transformer and voltage waveforms and schematic for a coupling factor of $\kappa=0.6$. Dotted lines represent points of complete energy transfer.

A Spiral Vector Inversion Generator is a variant of the well known Blumlein pulser which is capable of doubling the voltage to which the energy storage lines are charged. The Blumlein pulser is at best a voltage doubler and is commonly used to drive loads typical of that associated with many plasma loads. By contrast, a VIG is composed of two strip transmission-lines wound into a spiral that typically forms a hollow cylinder with output voltage 
determined by the number of turns in the VIG - "essentially a wound-up Blumlein." The two conducting strips are insulated from one another with a solid-dielectric film, with an additional film of dielectric included on the outside of the strip-line to provide turn-to-turn insulation as shown in Figure 2a. The net result is two parallel plate transmission lines, spirally wound, sharing a common conductor. The solid dielectric insulation is wider than the conductor width to provide a margin that inhibits edge-to-edge breakdown at high transient fields. In the highest voltage versions, techniques such as edge grading, potting, oils, or high-pressure gasses such as sulfur hexafluoride can be used to provide further edge-to-edge insulation.

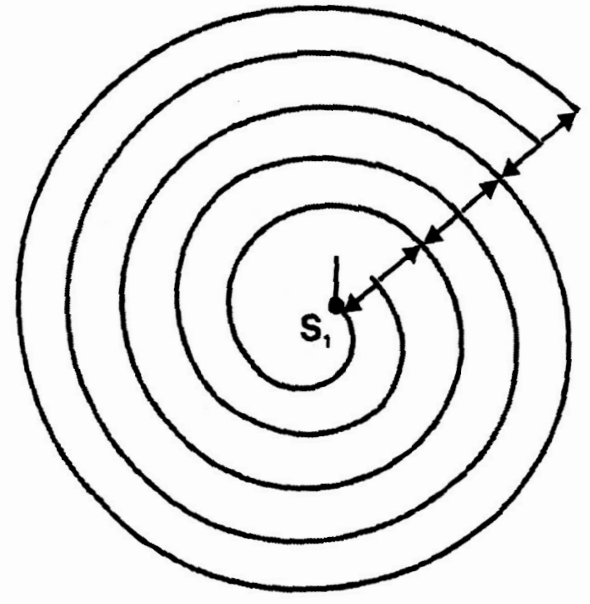

a)

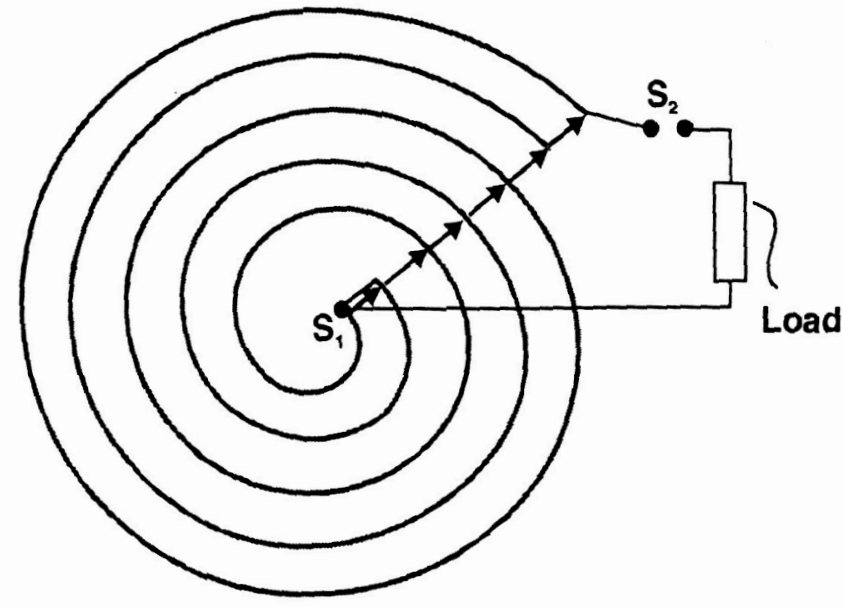

b)

Figure 2. Schematic of a spiral line Vector Inversion Generator. Solid lines are metal foils. The intermediate spaces are insulators. DC charged a), fully erected b)

During operation, the strip-line is dc charged to voltage of choice, usually between $1 \mathrm{kV}$ and $50 \mathrm{kV}$, with electrostatic energy stored in the capacitance $C_{i}$. A plotting of the field vectors, turn to-turn, shows that the array will either be electrically neutral or at the charge voltage, depending on the geometry. When a pulse is desired, the input switch, $S_{1}$ is triggered. This trigger action starts an electromagnetic wave traveling up one of the strip lines, but to a first approximation, due to the single-turn inductance, not in the second line. When the wave has propagated up the active line to the open end and reflected back to the switch $S_{1}$, the electric field vectors in the active line have been reversed, aligning the potential vectors radially. The net result is a transient high voltage between the lines at $S_{1}$ and the outermost turn on the VIG. The voltage-time waveform is a ramp function with risetime equal to two electrical wave transit-times, determined by the dielectric properties of the material in the lines, along the length of the spiral. Figure $1 \mathrm{~b}$ illustrates the vector inversion process within the generator at the instance that it is erected to full voltage. Assuming no losses, the peak voltage across the generator is $2 n V_{i}$ where $n$ is the number of turns and $V_{i}$ is the initial charge voltage. Losses and geometry reduce this to a fraction $\beta$ of the ideal amplitude. $\beta$ have at least three components. As the electromagnetic wave travels up the transmission lines, it is subject to attenuation due to the dielectric properties of the media in which it is traveling. A second loss factor is the inductance of the primary switch. For efficient switch performance, its impedance should be much less than the characteristic impedance of the strip line. A third loss factor is due to the inductance of a single turn of the spiral since it determines the rate at which the second strip line can discharge. In general, it is desirable to increase the discharge time for the second line as much as possible. For some geometries, $\beta$ can be as high as 0.95 and are usually associated with large diameters or small total line length. The output capacitance $\left(C_{o}\right)$ of the generator is derived by setting the initial stored energy equal to the output energy which results in the following relationship: 


$$
\frac{C_{i} V_{i}^{2}}{2}=\frac{C_{o} V_{o}^{2}}{2}
$$

Since $V_{0}=2 n V_{i}$ which it follows that:

$$
C_{o}=\frac{C_{i}}{(2 n)^{2}}
$$

Two options exist for utilizing the energy. The output can be connected directly to a load with the pulse wave form being a ramp function of voltage or an output switch can be utilized to connect the VIG to the load at an optimal point for maximum voltage. Depending on the output geometry, the waveform can be somewhat adjustable from a simple $C_{0} R_{l}$ waveform to a more "flat top" wave shape for many loads if the output switch is closed before the generator is finished erecting. In addition, passive elements such as transfer capacitors, non-linear elements, and pulse shaping lines can be added to produce almost any wave shape that might be needed for a particular load. For directly powering a load, it must always be kept in mind that the VIG voltage multiplication process is a dynamic one that continues to function as the energy is delivered to the load. As a general rule of thumb, when used to directly power a load, the VIG erection time should be long compared to the RC time constant in the load side of the circuit, $\tau \gg R_{1} C_{0}$. Voltages as high as one megavolt can be achieved with a pulse repetition rate determined by the basic energy store, the switch technology employed, and the desired life of the device.

Table 3 is a summary of the experimental data for a series of single-pulse generators built in our laboratory that illustrate the effect of diameter and hence "slow" circuit inductance on efficiency. Wherever possible, we tried to maintain the same switch geometry. The switch consisted of a "thumbtack" puncture switch that is commonly used in laboratory prototyping of high power devices. Similar results were obtained throughout the series of devices built.

\begin{tabular}{|l|l|l|l|l|l|l|l|}
\hline $\begin{array}{l}\text { \# turns n } \\
\text { on VIG }\end{array}$ & $\begin{array}{l}\text { Single } \\
\text { turn } \\
\text { diameter } \\
\text { D in cm }\end{array}$ & $\begin{array}{l}\text { Charge } \\
\text { Voltage } \\
\text { Vc }\end{array}$ & $\begin{array}{l}\text { Theoretical } \\
\text { Output } \\
\text { Voltage Vot }\end{array}$ & $\begin{array}{l}\text { Measured } \\
\text { Output } \\
\text { Voltage } \\
\text { Vom }\end{array}$ & $\begin{array}{l}\text { Efficiency } \\
\text { Vom/Vot }\end{array}$ & $\begin{array}{l}\text { Line } \\
\text { Length } \\
\text { In } \\
\text { meters }\end{array}$ & $\begin{array}{l}\text { Pulse } \\
\text { Risetime } \\
\text { ns }\end{array}$ \\
\hline 3 & 10 & 1000 & 6000 & 4800 & 0.8 & 0.94 & 20 \\
\hline 3 & 12.7 & 1000 & 6000 & 5040 & 0.84 & 1.20 & 25 \\
\hline 4 & 25.4 & 1000 & 8000 & 7000 & 0.89 & 3.20 & 34 \\
\hline $5^{*}$ & 2.5 & 1000 & 9200 & 10000 & 0.92 & 0.39 & 9 \\
\hline 10 & 24.1 & 3000 & 59000 & 32000 & 0.54 & 7.56 & 80 \\
\hline 10 & 100 & 2700 & 54,000 & 48600 & 0.90 & 31.4 & 1000 \\
\hline 40 & 45.7 & 30000 & 2400000 & 1000000 & 0.42 & 57.4 & $\sim 1500$ \\
\hline $50^{*}$ & 5.00 & 3500 & 354000 & 181000 & 0.51 & 7.97 & 88 \\
\hline
\end{tabular}

Table 3: Performance of a Series of VIGS to Demonstrate Diameter Scaling. The Entries with an * indicate Units that were Partially Loaded with Ferrite Material to Increase the Efficiency in Small Units.

Clearly there is a functional relationship between the value of $\mathrm{D} / \mathrm{n}$ and the voltage efficiency. This is understandable in the context that for a given diameter, the diameter determines the characteristic "speed" of the "slow" part of the VIG while the length which is directly proportional to n determines the characteristic "speed" of the fast side. The efficiency increases as the value of $D / n$ increases. The entries in Table 1 marked with * have partial ferrite loading to demonstrate the increases in efficiency that can be had with the applications of ferrites as discussed previously. Units with a low value of $\mathrm{D} / \mathbf{n}$ can be made highly efficient in dramatically smaller units. This is critical in weight and volume sensitive applications. This process must be optimized through the proper choice of ferrite materials properties and the amount of material needed to achieve the maximum result. Note that high efficiencies $(>50 \%)$ in small diameter devices are readily achievable. Since many plasma sources in general are 
sensitive to pulse rise time, also included in Table 3 are the rise times for each generator. These were calculated from:

$$
\tau=4 l \varepsilon^{0.5} / c
$$

where $l$ is the line length, $\varepsilon$ the relative dielectric constant (2.5-3.5 for foils used) and $\mathrm{c}$ is the velocity of light. The rise times are in agreement to within a few percent of that measured experimentally. In the table, we chose the theoretical values throughout since the bandwidth of the oscilloscope was somewhat limited for small rise times.

\section{Simple Pulsed Systems For Plasma Production}

\section{Pulsed Generator based on Double Resonant Pulse Transformer}

The DRPT shown in Figure 1 can be connected to an output switch to produce a simple high voltage-high current pulser that can drive low impedance plasma loads. Figure 3 shows the modification to the circuit in fig. 1 necessary. As before, a large capacitor $C_{1}$ is charged to a voltage $V$ and discharged through inductance $L_{1}$ in a close circuit that is resonant at a frequency governed by the values of $\mathrm{L}$ and $\mathrm{C}$. The secondary high voltage side of the transformer has component values chosen to achieve a given voltage step up. For a 10/1 transformation ratio, $\mathrm{L}_{2}$ is chosen to be 100 times the inductance $L_{1}$. Similarly, to keep the LC product the same on both sides, the condition for resonance, $C_{2}$ must be $0.01 C_{1}$. The physical layout of the system is such that the transformer coupling coefficient, $\mathrm{k}$, is $\mathbf{0 . 6}$. To make the system usable as a pulse generator, it is necessary to connect a load to the secondary, high voltage side of the system through an appropriate switch which in fig. 3 is labeled MS
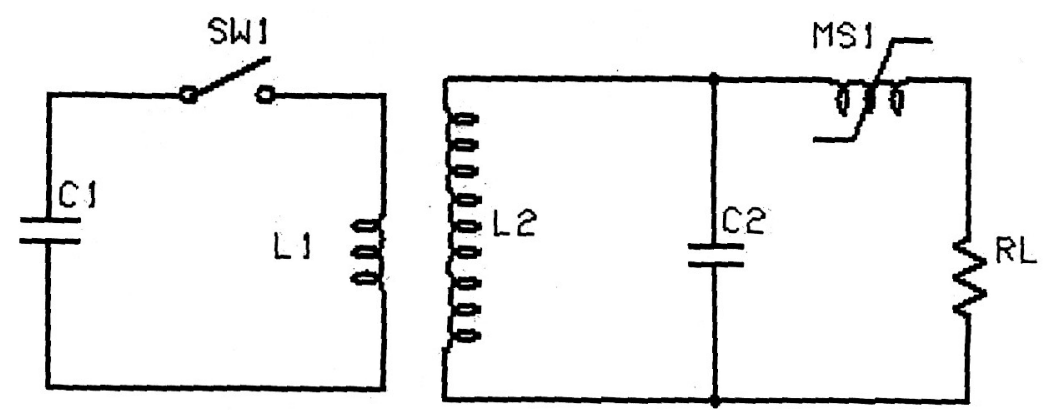

Figure 3. Schematic diagram of a pulsed electrical system based on a DRPT that can be used to drive a plasma load. The basic pulser consists of 5 components.

If long life is not an issue, $\mathrm{MS}_{1}$ can be replaced by a simple high pressure spark switch which using the appropriate gas, can be operated at a repetition rate of 10's of hertz. Figure 4 is a photograph of a DRPT high voltage pulse system in our laboratory. 


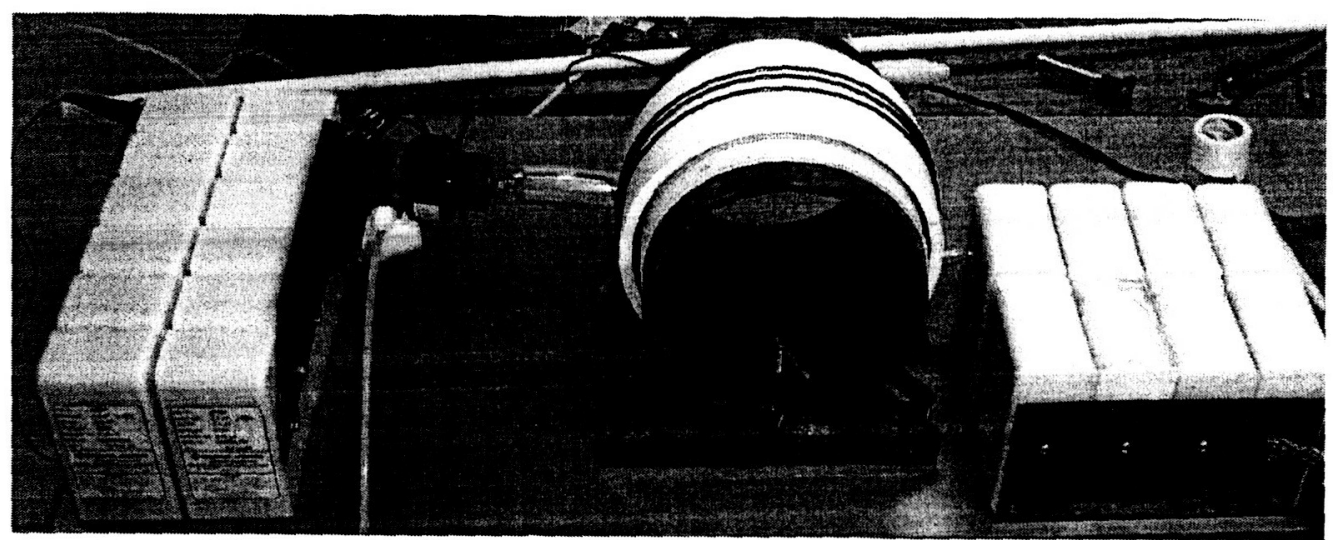

Figure 4. High voltage pulse generator based on a double resonant pulse transformer designed to operate at an input voltage of $5 \mathrm{kV}$ and an output voltage of $50 \mathrm{kV}$.

In Fig. 4, the high voltage capacitor is at the right. Also on the right side of the figure, there is a high pressure spark switch that can be pressurized to the point that it controls the deposition of energy to a suitable load. Figure 5 shows the voltage-time trace for the transformer under a no-load condition.

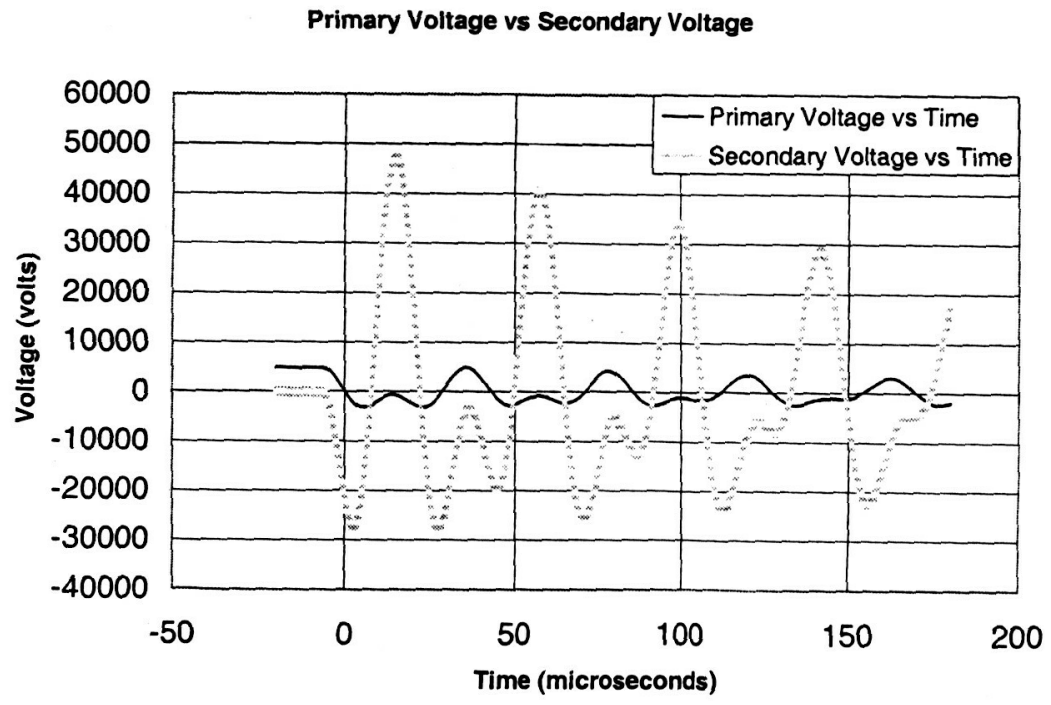

Figure 5. Voltage-time traces in both primary and secondary sides of the DRPT.

The specifications for this transformer are $\mathrm{C}_{1}=6 \mu \mathrm{F}, \mathrm{C}_{2}=0.06 \mu \mathrm{F}, \mathrm{L}_{1}=4.3 \mu \mathrm{H}, \mathrm{L}_{2}=443 \mu \mathrm{H}$. The charge voltage on $\mathrm{C}_{1}$ was $5 \mathrm{kV}$ and the maximum voltage on $\mathrm{C}_{2}$ was $48 \mathrm{kV}$. The voltage efficiency for the unit is about $96 \%$ which is excellent for this design. Note that when the voltage on $C_{1}$ is zero, the voltage on $C_{2}$ is maximum indicating complete energy transfer, minus losses, from the primary to the secondary side of the transformer. Since this design allows control of the rate at which energy is deposited into a load, desirable circuit dynamics are determined by the switch technology to be employed rather than the resonant frequency of the DRPT. For this design, solid state switches can readily be employed in the primary side of the circuit and a magnetic switch in the secondary side for high rep-rate operation with long life. Figure 6 illustrates the performance of the device shown in fig. 4 when the pressure on the output switch is adjusted to close at peak voltage. The load consists of two copper plates submerged in a saturated solution of copper sulfate. The load impedance is on the order of $0.25 \mathrm{Ohms}$. 


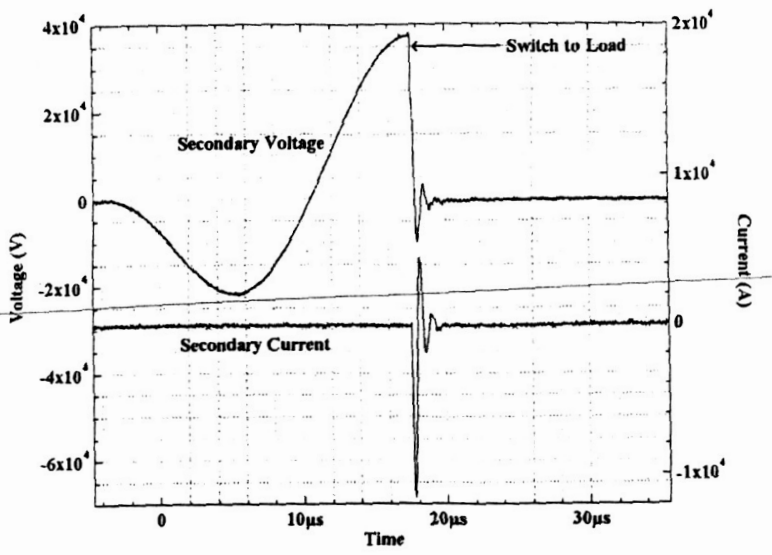

a)

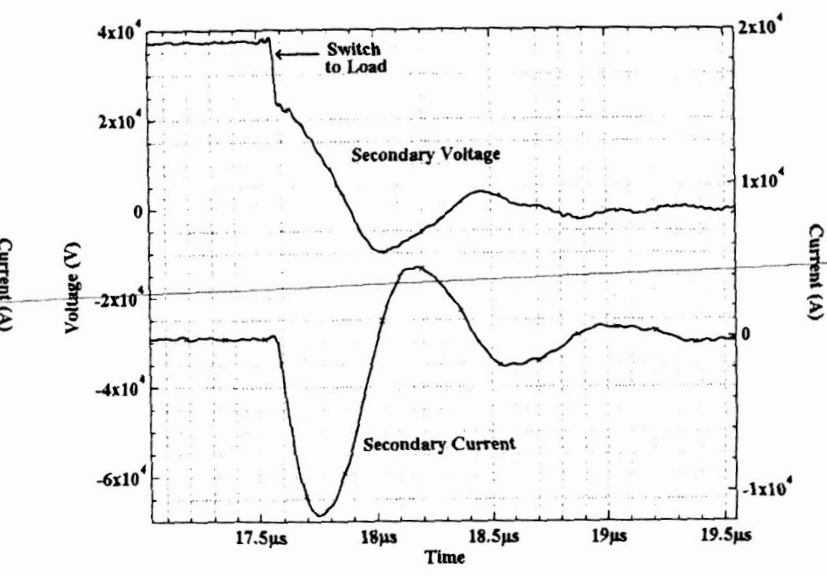

b)

Figure 6. Voltage-time and current-time traces for the DRPT switched into a low impedance load. a) trace showing initial waveform up to the point where switch closed. b) trace showing expanded time scale about the point where the switch closed.

In fig. 6 , the maximum current into the load was on the order of $12 \mathrm{kA}$ and the maximum $\mathrm{dL} / \mathrm{dt}$ was on the order of $100 \mathrm{kA} / \mu \mathrm{s}$. The technology demonstrated here scales readily to the hundreds of kiloamperes and comparable $\mathrm{dV} / \mathrm{dt}$.

\section{Pulse System based on Vector Inversion Generator}

Figure 7 a shows the physical embodiment of the device shown schematically in fig. 2 . As described previously, it consists of two metallic conductors, in this case, 0.002 mils of copper foil separated by 0.004 mils of capacitor grade polypropylene. To prevent edge margin breakdown, the dielectric foils are extended some 2 inches beyond the edges of the copper foil.

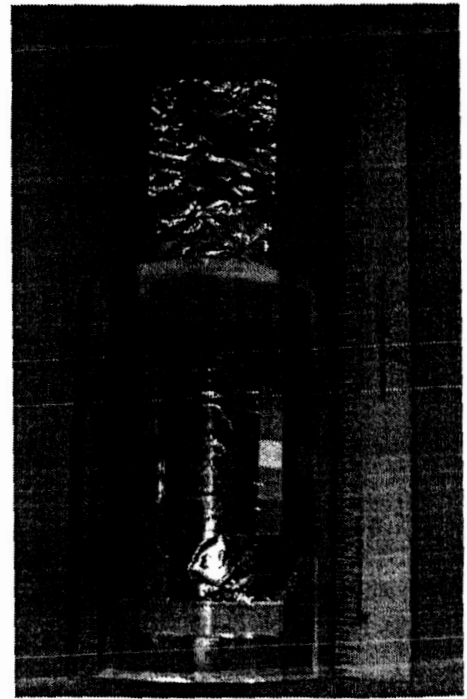

a)

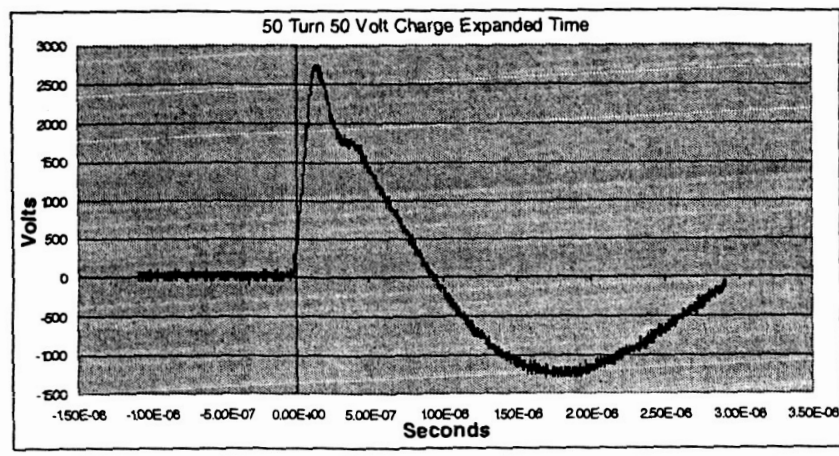

b)

Figure 7. a) Multi-turn VIG designed to produce high voltage RF pulses for plasma excitation. b) Experimental waveform for 50 turn VIG that is about $65 \%$ efficient. 
The ideal voltage-time waveform in a perfectly efficient VIG is that of a triangular "sawtooth" wave. In the unloaded case, that waveform will repeat. In practice, the waveform is as shown in fig. $7 \mathrm{~b}$. For driving a plasma, the VIG can be hard switched into the plasma or it can be made to oscillate at a frequency that is under the control of the designer. In any case, values of $\mathrm{dV} / \mathrm{dt}$ up to $1 \mathrm{MV} / \mu$ s are readily achievable at frequencies as high as $100 \mathrm{MhZ}$. Figure 8 shows two typical oscillatory waveforms that can routinely be produced and used to drive plasma loads by rf coupling to the plasma. Peak rf voltages as great as $100 \mathrm{kV}$ are readily achievable. However, above $50 \mathrm{kV}$ it is necessary to operate the units in oil or suitable potting compound to eliminate corona. The highest voltages achieved in our laboratory has been in excess of $1 \mathrm{MV}$. Life at these extreme voltages is limited. If however, the unit is to be used as a corona generator, a suitable knife edge or mesh structure is needed to provide the corona initiating structure. The rf energy can be coupled into a plasma with a helical structure wound around the plasma container or by a simple "wire antenna" in close proximity to the plasma container. Excitation begins within the rise time of the generator which can be on the order of nanoseconds. Needless to say, these devices represent substantial RFI sources and must be dealt with accordingly.

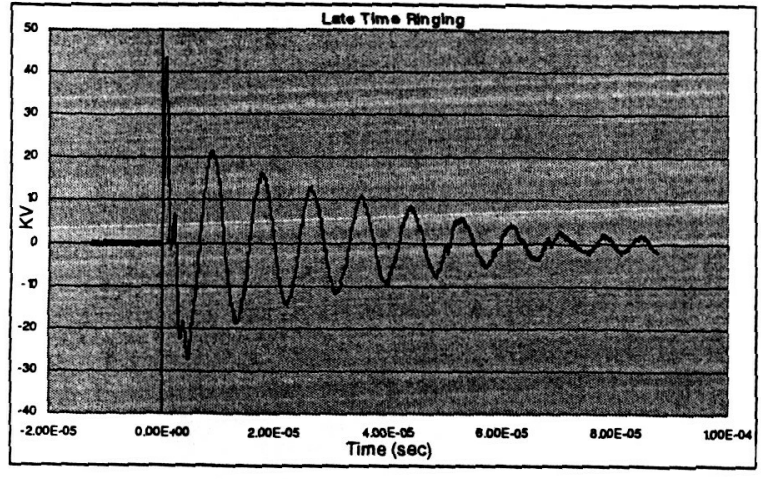

a)

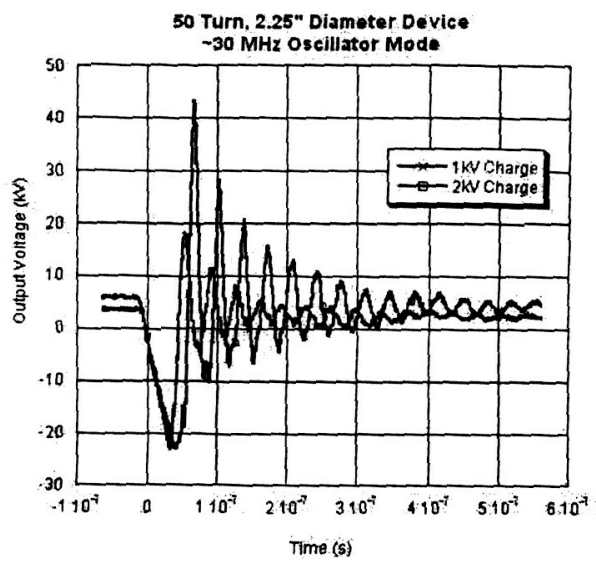

b)

Figure 8. Oscillatory discharge for two VIG devices. a) Low frequency VIG oscillating at a frequency of approximately $120 \mathrm{kHz}$. b) High frequency VIG oscillating at a frequency of approximately $30 \mathrm{MHz}$.

Figure 9 shows an example of rf excitation of a neon plasma at low pressure. It was excited by a simple wire antenna located on the axis of the protrusion into the chamber. The frequency of oscillation for the VIG was approximately $3 \mathrm{MHz}$ and was repetitively pulsed at a rate of $10 \mathrm{~Hz}$. Further experiments are planned with high speed cameras to study the dynamics of the plasma excitation as a function of gas pressure.

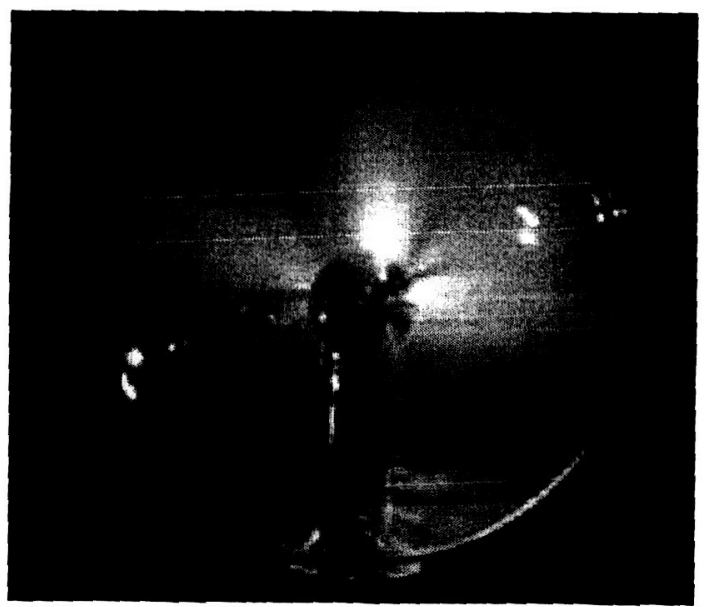

Figure 9. Neon plasma excitation with VIG oscillating at a frequency of $3 \mathrm{MHz}$. Peak RF voltage is on the order of $30 \mathrm{kV}$. Plasma was pulsed at a $10 \mathrm{~Hz}$ rate using a solid state switch. 


\section{Conclusions}

In this paper, we have shown that it is possible to build simple pulsed electrical circuits that are capable of repetitive operation. If an appropriate switch technology is used, these devices are capable of exceedingly long life with the basic failure rates being determined by the load circuits rather than the pulser itself. In order to get long life, capacitors and switches must be operated in a mode far away from the ultimate limits that would be possible if components were stressed to their limits. For the RF versions of VIG devices, plasma excitation in a helicon structure is now possible with a simple apparatus that is low cost and inherently rep-ratable and capable of volume excitation over a wide range of plasma pressures.

\section{Acknowledgements}

The work described in this paper was funded in part by the In-Space Propulsion Technology Program, which is managed by NASA's Science Mission Directorate in Washington, D.C., and implemented by the In-Space Propulsion Technology Office at Marshall Space Flight Center in Huntsville, Ala. The program objective is to develop in-space propulsion technologies that can enable or benefit near and mid-term NASA space science missions by significantly reducing cost, mass or travel times. The authors would also like to thank the Auburn Space Research Institute, Auburn University, and Radiance Technologies, Inc. for their support of this work.

\section{References}

1. "High Repetition Rate, Long Life Capacitors Developed for Laser Isotope Separation Modulators," V. Valencia, D. K. Haskell, R. A. Cooper, Proceedings of the IEEE Power Modulator Symposium, 181-185, 1982

2. "Pulsed Power Capability of High Energy Density Capacitors based on a New Dielectric Material," P. Winsor, T. Scholz, M. Hudis, K. M. Slenes, Proceedings of the 1999 International Pulsed Power Conference, 102-105, 1999

3. High Power Electronics, W. J. Sarjeant and R. E. Dollinger, ed., Chapter 6, "Spark Gaps", Tab Books, Inc. 1998

4. "Design Criteria for High Performance, High Power Pseudospark Switches," K. Frank, et. al., Proceedings of the $12^{\text {th }}$ International Pulsed Power Conference, IEEE Cat. \# 99CH36358 224-227, 1999

5. "Semiconductor Components up to $12 \mathrm{KV}$ and $150 \mathrm{KA}$ for Closing Switches," A. Wellman, E. Ramezani, J. Waldmeyer, S. Gekeninis, Proceedings of the $12^{\text {th }}$ International Pulsed Power Conference, IEEE Cat. \# 99CH36358 1268-1271, 1999

6. "Pulsed Power Generator Utilizing Fast SI-Thyristors for Environmental Applications," S. Ibuka, T. Osada, K. Jingushi, M. Suda, T. Nakamura, K. Yasuoka, S. Ishii, Proceedings of the $12^{\text {th }}$ International Pulsed Power Conference, IEEE Cat. \# 99CH36358, 1441-1444, 1999

7. "Pulse Switching Characteristics of Multi-Chip Flat Packaged 4500 V IGB," K. Okamura, F. Endo, K. Atsmi, K. Yokokura, Proceedings of the $12^{\text {th }}$ International Pulsed Power Conference, IEEE Cat. \# 99CH 36358, $1492-1495$

8. "Prototype 2-Stage Magnetic Pulse Compression Modulator for Pulse Power Applications," J. S. Oh, S. S. Park, S. d. Jang, M. H. Chok, I. S. Ko, W. Namkung, Proceedings of the 1996 International Power Modulator Symposium, 186-189, IEEE Cat. \# 96CH35877.

9. "Magnetic Modulator Lifetime Tests using the Sandia Reliability Test-Bed," K. W. Reed, L. X. Schneider, G. E. Pena, L. E. Martinez, Proceedings of the $12^{\text {th }}$ International Pulsed Power Conference, IEEE Cat. \# 99CH36358, 528531,1999

10. Fitch, R. A. and Howell, R. T. S., "Novel Principle of a Transient High Voltage Generator," Proc. IEE, Vol. III, No. 4, April 1964. 